\title{
Comparison of the peripheral blood eosinophil count using near-patient testing and standard automated laboratory measurement in healthy, asthmatic and COPD subjects
}

\author{
This article was published in the following Dove Press journal: \\ International Journal of COPD \\ 26 September 2017 \\ Number of times this article has been viewed
}

\section{Kirsty Hambleton \\ Clare M Connolly \\ Catherine Borg \\ Joanne H Davies \\ Helen $P$ Jeffers \\ Richard EK Russell \\ Mona Bafadhel}

Respiratory Medicine Unit, Nuffield Department of Clinical Medicine, University of Oxford, Oxford, UK
Correspondence: Mona Bafadhel Respiratory Medicine Unit, Nuffield Department of Medicine, University of Oxford, NDM Research Building, Oxford OX3 7FZ, UK

Email mona.bafadhel@ndm.ox.ac.uk

\begin{abstract}
Near-patient testing (NPT) allows clinical decisions to be made in a rapid and convenient manner and is often cost effective. In COPD the peripheral blood eosinophil count has been demonstrated to have utility in providing prognostic information and predicting response to treatment during an acute exacerbation. For this potential to be achieved having a reliable NPT of blood eosinophil count would be extremely useful. Therefore, we investigated the use of the HemoCue ${ }^{\circledR}$ WBC Diff System and evaluated its sensitivity and specificity in healthy, asthmatic and COPD subjects. This method requires a simple skin prick of blood and was compared to standard venepuncture laboratory analysis. The HemoCue ${ }^{\circledR}$ WBC Diff System measured the peripheral blood eosinophil count in healthy, asthma and COPD subjects with very close correlation to the eosinophil count as measured by standard venepuncture. The correlations were unaffected by disease status. This method for the measurement of the peripheral blood eosinophil count has the potential to provide rapid near-patient results and thus influence the speed of management decisions in the treatment of airway diseases.
\end{abstract}

Keywords: asthma, chronic obstructive pulmonary disease, eosinophils, near-patient testing

\section{Introduction}

Modern medical practice is often constrained due to an environment of time and resource limitation, and mechanisms to counteract this are actively sought; rapid and accurate bedside diagnostic tools, such as near-patient tests (NPTs) are one such mechanism. ${ }^{1}$ NPTs provide rapid results and can guide treatment decisions; ${ }^{2}$ having been established in clinical care guidelines for the management of chronic kidney disease ${ }^{3}$ and diabetes. ${ }^{4}$ In respiratory medicine, current NPTs include the oxygen saturation probe, the peak flow meter, exhaled nitric oxide and the spirometer. Although able to provide an immediate result, these current respiratory NPTs are limited in their ability to identify treatment response. ${ }^{5,6}$ Changes in serial peak flow readings are able to confirm a history of occupational asthma ${ }^{7}$ and worsened outcomes following an acute exacerbation, ${ }^{8}$ but provide no information regarding inflammatory state ${ }^{9}$ or airways treatable trait. ${ }^{10}$ The sputum and peripheral blood eosinophil count (PBEC) has been shown to be a useful measure in determining corticosteroid response in airways disease. ${ }^{11-15}$ Exhaled nitric oxide is a good surrogate of eosinophilic airway inflammation but is affected by smoking. ${ }^{16}$ The HemoCue ${ }^{\circledR}$ WBC Diff System (HemoCue AB, Ängelholm, Sweden) is a portable NPT, offering a 5-point differential full blood count within 2 minutes from a single drop of blood. ${ }^{17}$ This technology 
has been evaluated by one group in 76 patients with severe asthma (Heffler et $\mathrm{al}^{18}$ ) and they found there to be a good correlation between the HemoCue system and standard laboratory measurements of blood eosinophils. It is unknown how this NPT method is in patients with COPD and also in healthy adults. We thus evaluated the HemoCue WBC Diff System NPT against matched automated laboratory results to assess its sensitivity and specificity in measuring PBEC in healthy adults and patients with airways disease.

\section{Methods}

A comparison of peripheral blood leukocyte counts from the HemoCue WBC Diff NPT device against corresponding laboratory automated results (Abbott Architect ci8200; Abbott Laboratories, Abbott Park, IL, USA) was conducted from healthy controls and subjects with asthma and COPD. Whole venous blood $(5 \mathrm{~mL}$ in ethylene-diamine-tetra-acetic acid [EDTA] prepared tube) was taken via venepuncture and delivered to the local pathology laboratory at the Oxford University Hospitals NHS Foundation Trust. Following venepuncture a pin-prick of blood was also taken (one drop, approximately $10 \mu \mathrm{L}$ ) and analyzed with the results being reported immediately. Allergy status was determined by a self-reported history of atopy. Correlations and intra-class correlation coefficients (ICCs) were calculated to measure relationships between the NPT and automated laboratory results for eosinophil, neutrophil and total leukocyte cell counts (cells $\times 10^{9} / \mathrm{L}$ ). Sensitivity and specificity for identifying percentage PBEC were also calculated. Bland-Altman plots were generated to assess proportional bias. In a separate subgroup of subjects with COPD ( $n=20)$, up to three drops of blood were measured for assessment of variation with repeated sampling. The lower limit of detection of PBEC for the NPT and laboratory automated analyzer was 0.1 and $0.03 \times 10^{9}$ cells/L. Ethical approval was obtained from the Leicestershire, Northamptonshire and Rutland Ethics Committee (08/H0406/189) and all volunteers provided written informed consent.

\section{Results}

In the comparison study, 41 subjects (20 men) were recruited, with a mean age (range) of 47 (23-79) years. This consisted of 19 healthy controls, 12 asthma and 10 COPD subjects. A self-reported history of atopy occurred in $11(30 \%)$. The geometric means (95\% confidence interval [CI]) for all subjects for total leukocytes, neutrophils and eosinophils measured using the NPT device were 6.3 (5.3-7.3), $3.5(2.8-4.4)$ and $0.2(0.1-0.2) \times 10^{9}$ cells/L respectively and for automated laboratory results were 7.1 (6.4-7.9), $4.3(3.7-4.9)$ and $0.2(0.1-0.2) \times 10^{9}$ cells/L respectively. For percentage eosinophils, the mean (SD) for the NPT device and automated results were 3.4 (3.6) and 3.1 (3.3) respectively. Paired analysis demonstrated no differences of PBEC between the NPT and automated laboratory analyzer for absolute and $\% \operatorname{PBEC}(p=0.78$ and $p=0.29$, respectively).
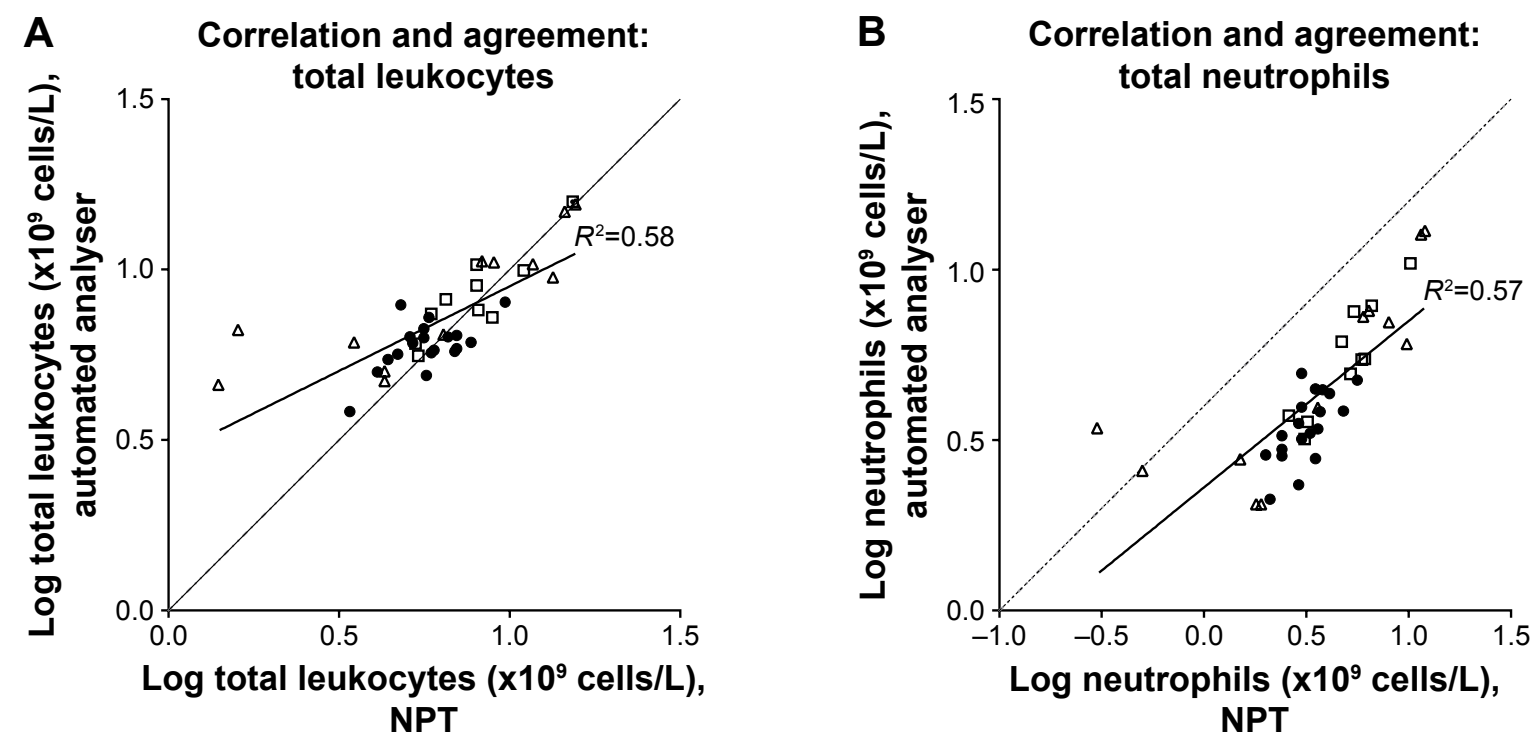

- Regression line …..... Equality line

Figure I (Continued) 

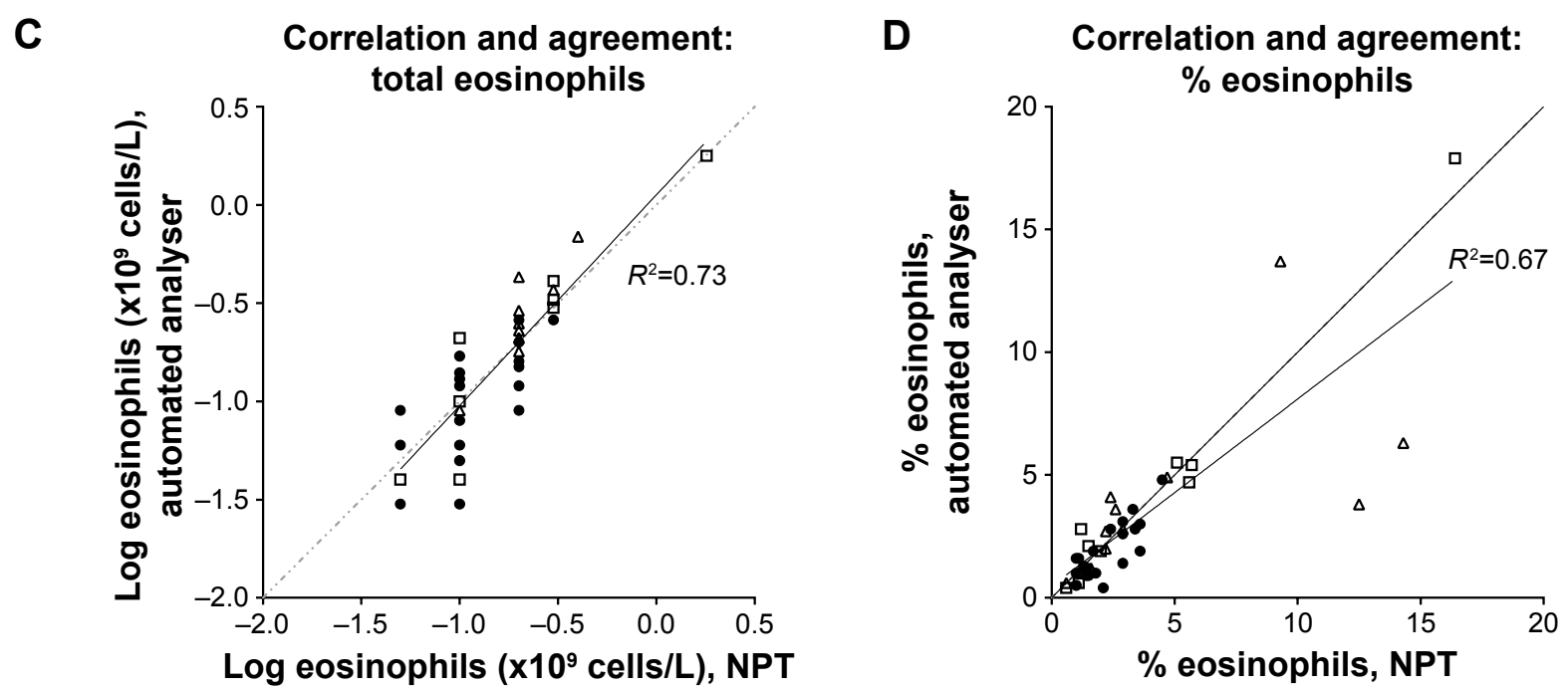

\section{Regression line ........ Equality line}
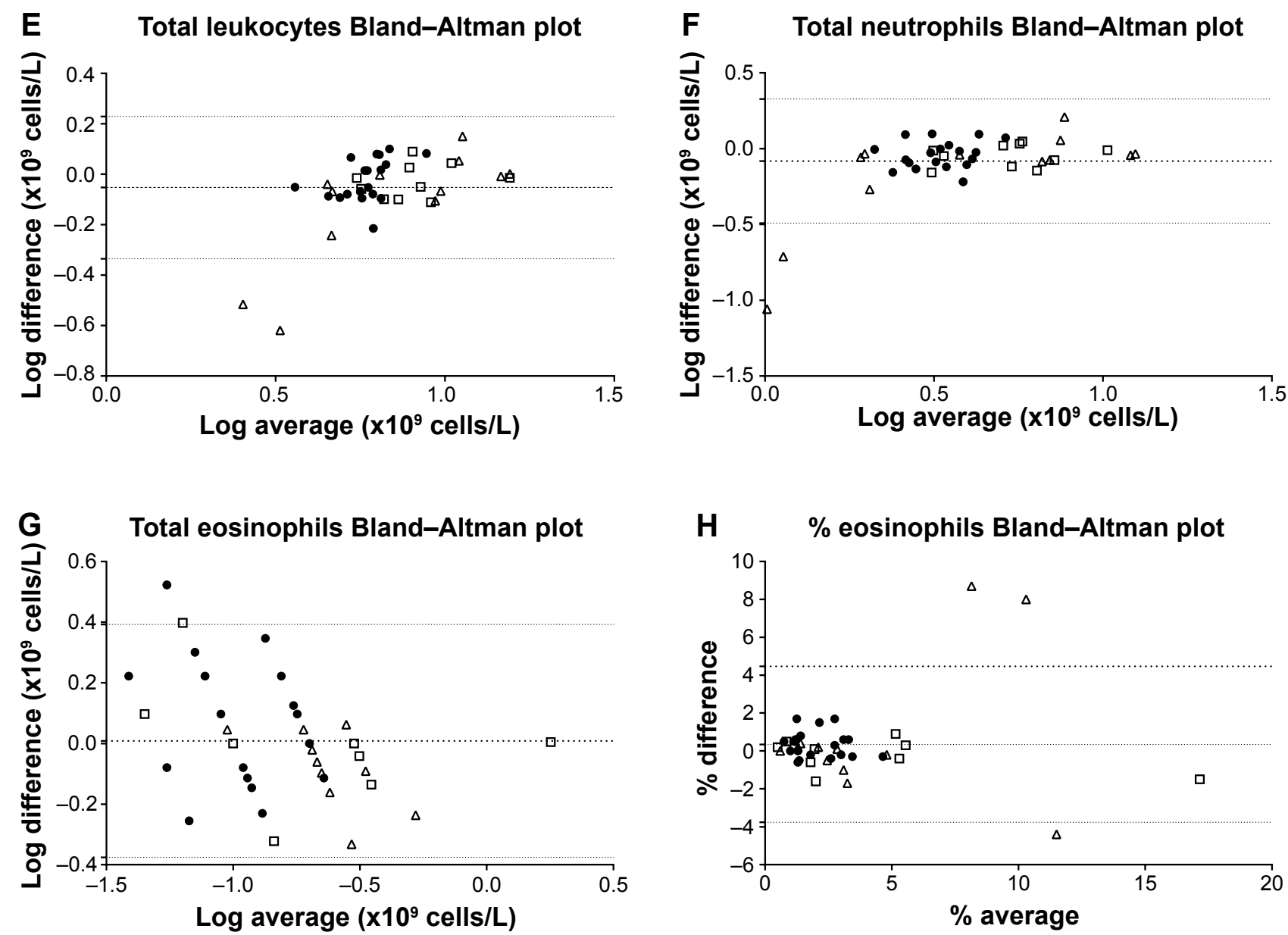

Figure I (A-D) Correlation and agreement plots for total leukocyte, neutrophil and eosinophil cell counts $\left(\times 10^{9}\right.$ cells/L) between NPT (HemoCue ${ }^{\circledR}$ WBC Diff System; HemoCue AB, Ängelholm, Sweden) and automated laboratory analyser (Abbott Architect ci8200; Abbott Laboratories, Abbott Park, IL, USA). $\bullet$ Healthy volunteer controls; $\square$ COPD; $\Delta$ asthma. (E-H) Bland-Altman plots for total leukocyte, neutrophil and eosinophil cell counts $\left(\times 10^{9}\right.$ cells/L), difference and average between NPT (HemoCue ${ }^{\circledR}$ WBC Diff System) and automated laboratory analyzer (Abbott Architect ci8200). Horizontal lines set at bias and upper and lower $95 \% \mathrm{Cl}$ of the bias. $\bullet$ Healthy volunteer controls; $\square$ COPD; $\Delta$ asthma.

Abbreviations: $\mathrm{Cl}$, confidence interval; NPT, near-patient testing. 
Strong correlations and agreement, presented in Figure 1, were seen for all subjects (total eosinophils $r=0.85$; total neutrophils $r=0.75$; and total leukocytes, $r=0.76)$. The mean ICC $(95 \%$ CI) for percentage PBEC was 0.89 (0.74-0.95) and total PBEC was $0.98(0.95-0.99)$ respectively. This indicates minimal variability between the results using NPT and automated analyzer. Atopy did not affect these results. In subjects with asthma or COPD, the NPT identified a blood eosinophil level of above or below $2 \%$, determined by the automated laboratory analyzer as the gold standard, correctly in $20(91 \%)$ with a sensitivity and specificity of $94 \%$ and $83 \%$ respectively. At high levels of \% eosinophils proportional bias was noted (Figure $1 \mathrm{H}$ ). In the repeatedsampling sub-study of COPD subjects, the intra-class coefficient $(95 \% \mathrm{CI})$ of total leukocytes, total neutrophils and total eosinophils was 0.95 (0.82-0.98), $0.90(0.74-0.97)$ and $0.90(0.73-0.96)$ respectively, with a Cronbach Alpha reliability statistic of $>0.95$ for each measure.

\section{Conclusion}

The NPT HemoCue WBC Diff device, using a pin-prick of blood sample, is comparable to an automated Abbott Architect ci8200 laboratory analyzer when measuring PBEC levels and total cell counts in whole blood in both healthy volunteers and individuals with airways disease. This result was not affected by a self-reported history of allergy, is minimally variable and has excellent sensitivity in correctly identifying a percentage $\mathrm{PBEC}$ level $\geq 2 \%$. There was excellent agreement and correlation of the PBEC measured in the NPT, with very close margins of agreement. Proportional bias at higher levels of $\%$ eosinophil counts were seen, however, if this NPT was to be used for quantification of a binary outcome threshold of $2 \%$ to make treatment decisions regarding corticosteroids ${ }^{12}$ then this proportional bias at higher levels of PBEC is not clinically significant. Repeated sampling, in patients with COPD, was also found to be excellent. We suggest that this NPT can be used to measure eosinophil counts in patients with asthma and COPD.

\section{Acknowledgments}

The authors would like to acknowledge all the volunteers for their assistance in this study. Mona Bafadhel is funded by a National Institute of Health Research (NIHR) Post-doctoral Fellowship (PDF-2013-06-052). This paper presents independent research funded by the National Institute of Health Research and the views expressed are those of the authors and not necessarily those of the NHS, the NIHR or the Department of Health.

\section{Author contributions}

All authors contributed toward data analysis, drafting and critically revising the paper, gave final approval of the version to be published, and agree to be accountable for all aspects of the work.

\section{Disclosure}

$\mathrm{MB}$ and REKR have received honoraria from AstraZeneca, Boehringer Ingelheim, Chiesi, Novartis and Pfizer, and report no other conflicts of interest in this work. $\mathrm{KH}$, $\mathrm{CMC}, \mathrm{CB}, \mathrm{JHD}$, and HPJ report no conflicts of interest in this work.

\section{References}

1. Crook MA. Near patient testing and pathology in the new millennium. J Clin Pathol. 2000;53(1):27-30.

2. Fitzmaurice DA, Hobbs F, Murray ET, Holder RL, Allan TF, Rose PE. Oral anticoagulation management in primary care with the use of computerized decision support and near-patient testing: A randomized, controlled trial. Arch Intern Med. 2000;160(15):2343-2348.

3. National Institute of Clinical Excellence. Chronic kidney disease in adults: assessment and management. 2014. Available from: https:// www.nice.org.uk/Guidance/cg182. Accessed August 17, 2017.

4. National Insitute of Clinical Excellence. Type 2 diabetes in adults: management. 2015. Available from: https://www.nice.org.uk/guidance/ ng28. Accessed August 17, 2017.

5. Jensen LA, Onyskiw JE, Prasad NGN. Meta-analysis of arterial oxygen saturation monitoring by pulse oximetry in adults. Heart Lung. 1998;27(6):387-408.

6. Izbicki G, Abboud S, Jordan P, Perruchoud AP, Bolliger CT. A comparison of a new transtelephonic portable spirometer with a laboratory spirometer. EurRespir. 1999;14(1):209-213.

7. Burge CB, Moore VC, Pantin CF, Robertson AS, Burge PS. Diagnosis of occupational asthma from time point differences in serial PEF measurements. Thorax. 2009;64:1032-1036.

8. Birring SS, Heartin E, Williams TJ, Brightling CE, Pavord ID. Peak expiratory flow sequence in acute exacerbations of asthma. BMJ. 2001; 322(7297): 1281.

9. Haldar P, Pavord ID, Shaw DE, et al. Cluster analysis and clinical asthma phenotypes. Am J Respir Crit Care Med. 2008;178(3):218-224.

10. Agusti A, Bel E, Thomas M, et al. Treatable traits: toward precision medicine of chronic airway diseases. Eur Respir J. 2016;47(2):410-419.

11. Green RH, Brightling CE, McKenna S, et al. Asthma exacerbations and sputum eosinophil counts: a randomised controlled trial. Lancet. 2002; 360(9347):1715-1721.

12. Bafadhel M, McKenna S, Terry S, et al. Blood eosinophils to direct corticosteroid treatment of exacerbations of chronic obstructive pulmonary disease: a randomized placebo-controlled trial. Am J Respir Crit Care Med. 2012;186(1):48-55.

13. Bafadhel M, Davies L, Calverley PM, Aaron SD, Brightling CE, Pavord ID. Blood eosinophil guided prednisolone therapy for exacerbations of COPD: a further analysis. Eur Respir J. 2014;44(3): 789-791.

14. Watz H, Tetzlaff K, Wouters EF, et al. Blood eosinophil count and exacerbations in severe chronic obstructive pulmonary disease after withdrawal of inhaled corticosteroids: a post-hoc analysis of the WISDOM trial. Lancet Resp Med. 2016;4(5):390-398.

15. Siva R, Green RH, Brightling CE, et al. Eosinophilic airway inflammation and exacerbations of COPD: a randomised controlled trial. Eur Respir J. 2007;29(5):906-913.

16. Barnes PJ, Dweik RA, Gelb AF, et al. Exhaled nitric oxide in pulmonary diseases: a comprehensive review. Chest. 2010;138(3):682-692. 
17. Osei-Bimpong A, Jury C, McLean R, Lewis SM. Point-of-care method for total white cell count: an evaluation of the HemoCue WBC device. In J Lab Hematol. 2009;31(6):657-664.
18. Heffler E, Terranova G, Chessari C, et al. Point-of-care blood eosinophil count in a severe asthma clinic setting. Ann Allergy Asthma Immunol. 2017;119(1):16-20.

International Journal of COPD

\section{Publish your work in this journal}

The International Journal of COPD is an international, peer-reviewed journal of therapeutics and pharmacology focusing on concise rapid reporting of clinical studies and reviews in COPD. Special focus is given to the pathophysiological processes underlying the disease, intervention programs, patient focused education, and self management protocols
Dovepress

This journal is indexed on PubMed Central, MedLine and CAS. The manuscript management system is completely online and includes a very quick and fair peer-review system, which is all easy to use. Visit $\mathrm{http}: / / \mathrm{www}$.dovepress.com/testimonials.php to read real quotes from published authors.

Submit your manuscript here: http://www.dovepress.com/international-journal-of-chronic-obstructive-pulmonary-disease-journal 